\title{
Structure-switching hairpin probe based electrochemical aptasensor for highly sensitive detection of protein
}

\author{
Xia Hu${ }^{1}$, Song-Bai Zhang, a , Ji-Lin Lu ${ }^{1,}$ b, Li-Ying Zheng ${ }^{1}$, Hong-En Geng ${ }^{1}$, \\ Yan-Qing Qiu ${ }^{1}$, Yan-Yan Huang ${ }^{1}$, Li-Ping Qiu ${ }^{2}$ and Yuan-Dao Chen ${ }^{1}$ \\ ${ }^{1}$ College of Chemistry and Chemical Engineering, Hunan University of Arts and Science, \\ Changde 415000, PR China \\ ${ }^{2}$ State Key Laboratory for Chemo/Biosensing and Chemometrics, College of Chemistry and \\ Chemical Engineering, Hunan University, Changsha 410082, PR China \\ azb0119@163.com, blu736@163.com
}

Keywords: Aptasensor, structure-switching, hairpin probe, electrochemical, PDGF-BB

Abstract. Using platelet derived growth factor B chain (PDGF-BB) as the model analyte, a structure-switching hairpin probe based electrochemical biosensing strategy for highly sensitive detection of protein is proposed in this work. Aptamer probe hybridized with the immobilized hairpin structured signal probe to form DNA duplex. Upon binding with target protein, competition between target molecule and the signal probe with the aptamer probe happened, inducing the signal probe from stretched duplex to hairpin structure. Under optimum experimental conditions, the target protein can be sensitively detected in a linear dynamic range from $0.1 \mathrm{ng} / \mathrm{mL}$ to $500 \mathrm{ng} / \mathrm{mL}$ with a low detection limit of $0.08 \mathrm{ng} / \mathrm{mL}$.

\section{Introduction}

Traditionally, antibody-antigen specific reaction based immunoassay is the main analysis technique for protein. However, due to the inherent drawbacks such as the weak stability for preserving of antibody and the long term for synthesis, the application of immunoassay technique is limited to some extent $[1,2]$. Recently, a new class of recognition element for proteins named aptamer has been widely studied due to its numerous advantages such as good stability, simple synthesis, easy labeling and high affinity and specificity when binding with targets [3]. Lots of aptamer based biosensing methods have been delevoped including colorimetric, fluorescent, electrochemical, and so on [4-8]. Thereinto the electrochemical strategies have attracted the most attention because of their numerous merits including high sensitivity, low cost, small dimensions and compatibility with microfabrication technology $[9,10]$.

In the proposed work, a structure-switching hairpin probe based electrochemical biosensing strategy was developed for highly sensitive detection of proteins using PDGF-BB as the model analyte. Fabrication and detection principle of the electrochemical aptasensor are shown in Figure 1.

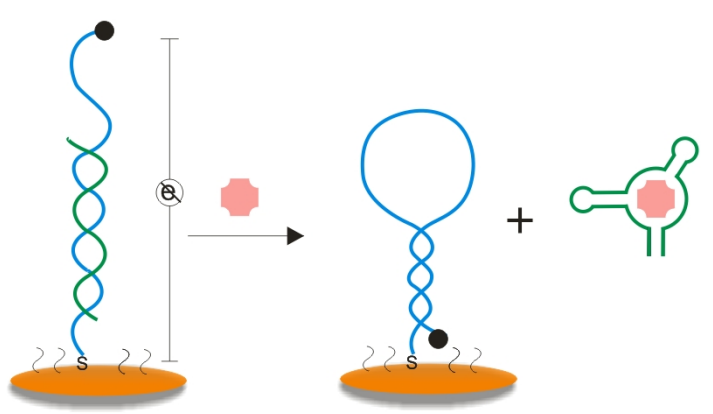

Figure 1. Scheme illustration of fabrication and operation principle of the proposed biosensor.

The sensing interface was fabricated by firstly self-assembling 5 '-mercapto modified signal probe on the gold electrode followed by blocking with 6-mercaptohecanol and hybridizing with the aptamer probe. By measuring the ac current voltammetry, the target protein could be sensitively detected with 
a low detection limit as well as a wide linear dynamic range. The experimental conditions were optimized, and the performance features such as reproducibility and stability were also evaluated.

\section{Materials and Methods}

Materials. Oligonucleotides utilized in this study were all synthesized by Sangon Biotechnology Co., Ltd. (Shanghai, China). The sequence of aptamer probe was CAGGCTACGGCACGTAGAGCATCACCA TGATCCTG (5'-3'), and the sequence of signal probe was SH-CGACTGTTTTGATGCTCTACGTAC TGGCAGTCG-Ferrocene (5'-3'). PDGF-BB, PDGF-AA, PDGF-AB, IgG, BSA and Tris were all obtained from Dingguo Biotechnology Co., Ltd. (Changsha, China). Tris- $\mathrm{HCl}$ buffer (10 mM Tris, $0.3 \mathrm{M} \mathrm{NaCl}, 5 \mathrm{mM} \mathrm{MgCl}, \mathrm{pH} 7.8$ ) was used as stock solution and working solutions. Deionized and sterilized water was used throughout the experiments. All other chemicals were of analytical reagent grade and used as received.

Fabrication of the aptasensor. Firstly, the gold electrode was pretreated according to reference [8]. Then, $20 \mu \mathrm{L}$ of signal probe solution was dipped onto the gold electrode to self-assemble for $2 \mathrm{~h}$ followed by blocking with $20 \mu \mathrm{L}$ of $5 \mathrm{mM}$ 6-mercaptoethanol solution for $15 \mathrm{~min}$ to inactivate the nonspecific sites. Finally, $20 \mu \mathrm{L}$ of aptamer solution was dropped on the electrode surface to hybridize $1 \mathrm{~h}$ and the sensing interface was fabricated.

Electrochemical measurements. All electrochemical measurements were carried out in a self-made measuring cell at ambient temperature using a $\mathrm{CHI} 660 \mathrm{E}$ electrochemical workstation (Chenhua Instruments, China). A conventional three-electrode system was used: a gold electrode of interest as working electrode, a saturated calomel electrode (SCE) as reference electrode, and platinum foil as auxiliary electrode. Cyclic voltammetry (CV) was implemented in $5 \mathrm{~mL}$ of $10 \mathrm{mM}$ PBS (pH 7.4) containing $5 \mathrm{mM} \mathrm{Fe}(\mathrm{CN})_{6}{ }^{3-} / \mathrm{Fe}(\mathrm{CN})_{6}{ }^{4-}$ and $0.1 \mathrm{M} \mathrm{KCl}$ at a scan rate of $100 \mathrm{mV} / \mathrm{s}$. For target protein detection, $20 \mu \mathrm{L}$ of PDGF-BB solution with a certain concentration was placed onto the sensing interface to incubate for $1 \mathrm{~h}$. After rinsing with the stock buffer, AC voltammogram was performed in $1 \mathrm{M} \mathrm{NaClO}_{4}$ at a frequency of $1 \mathrm{~Hz}$, and the peak current was used to evaluate the response characteristics of sensing interface.

\section{Results and discussion}

Influence of reaction temperature. The reaction temperature directly influenced the sensor fabrication from three aspects: the hybridization reaction between hairpin signal probe and aptamer probe, the melting of hairpin signal probe and the activity of protein. In order to investigate the effect of reaction temperature on the analytical performance of the proposed sensor, $20 \mu \mathrm{L}$ of $500 \mathrm{ng} / \mathrm{mL}$ PDGF-BB was placed on the sensing interface and allowed to incubate at a certain temperature for $1 \mathrm{~h}$, and the results was shown in Fig. $2 \mathrm{~A}$. The change of peak current ( $\Delta I_{\text {peak }}$, defined as $\mathrm{I}_{0}-\mathrm{I}$ where $\mathrm{I}_{0}$ was the peak current before reacting with target protein and I was the peak current after reacting with target protein) increased gradually and tended to maximum at about $37{ }^{\circ} \mathrm{C}$. When the reaction temperature increased continuously, the peak current decreased sharply due to the fact that relatively high reaction temperature would induce dehybridization of the duplex and inactivation of the target protein. In order to get the highest response current, all of the experiments were carried out at $37^{\circ} \mathrm{C}$ except stated otherwise.

Effect of incubation time. The incubation time also influenced the analytical performances of the presented electrochemical aptasensor. In order to optimize the incubation time, $20 \mu \mathrm{L}$ of $500 \mathrm{ng} / \mathrm{mL}$ target protein was dropped on the electrode surface. The specific reaction was allowed to maintain for different periods of time and the results was shown in Fig. 2B. The change of peak current increased gradually with the augment of incubation time and then tended constant when the reaction time was more than $60 \mathrm{~min}$ since the reaction equilibrium was reached. Therefore, $60 \mathrm{~min}$ was chosen as the optimum incubation time in following experiments to ensure the completeness of the reaction. 

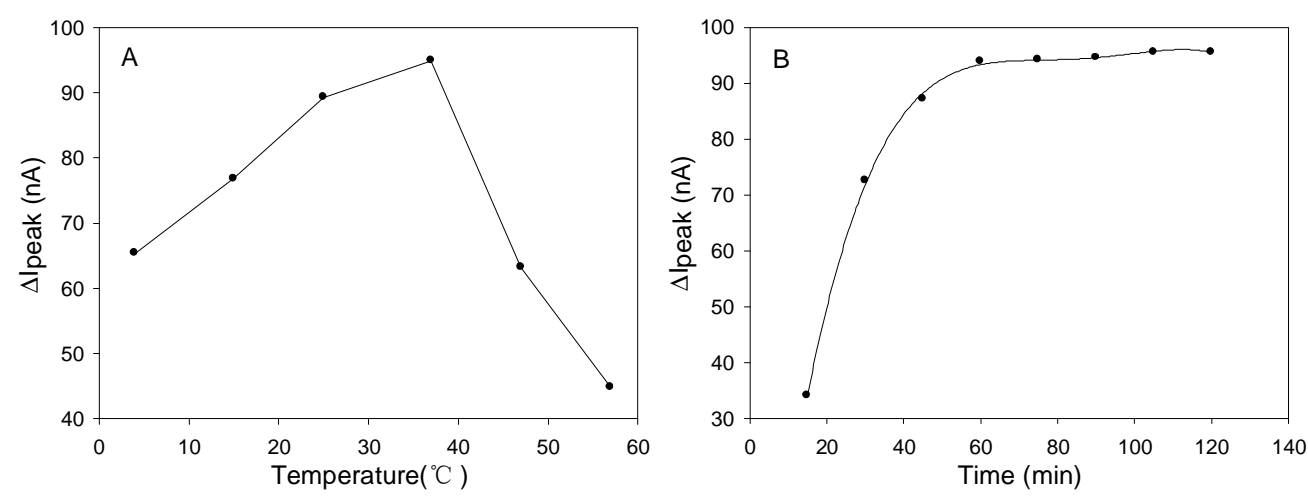

Figure 2. (A) Influence of reaction temperature. Six typical temperatures $\left(4,15,25,37,47\right.$ and $\left.57{ }^{\circ} \mathrm{C}\right)$ were investigated with target protein concentration of $500 \mathrm{ng} / \mathrm{mL}$. (B) Effect of incubation time. Different periods of time $(15,30,45,60,75,90,105$ and $120 \mathrm{~min})$ was investigated with target protein concentration of $500 \mathrm{ng} / \mathrm{mL}$.

Detection of target protein. In order to evaluate the analytical performances of the proposed biosensor, a series of samples with different concentrations were detected under the optimized experimental conditions and the results was shown in Fig. 3A. The current change $\left(\Delta I_{\text {peak }}\right)$ increased with the augment of the concentration of target protein. A wide linear relationship between the current change versus the log concentration of PDGF-BB was achieved in the concentration range from 0.1 to $500 \mathrm{ng} / \mathrm{mL}$ with a correlation coefficient of $0.9982(\mathrm{n}=5$, R.S.D. $=8.3 \%$, as shown in Fig. 3B). The calibration equation was $\Delta I_{\text {peak }}=24.1126 \log C+27.6997$. The detection limit was $0.08 \mathrm{ng} / \mathrm{mL}$ based on a signal-to-noise ratio of 3 .
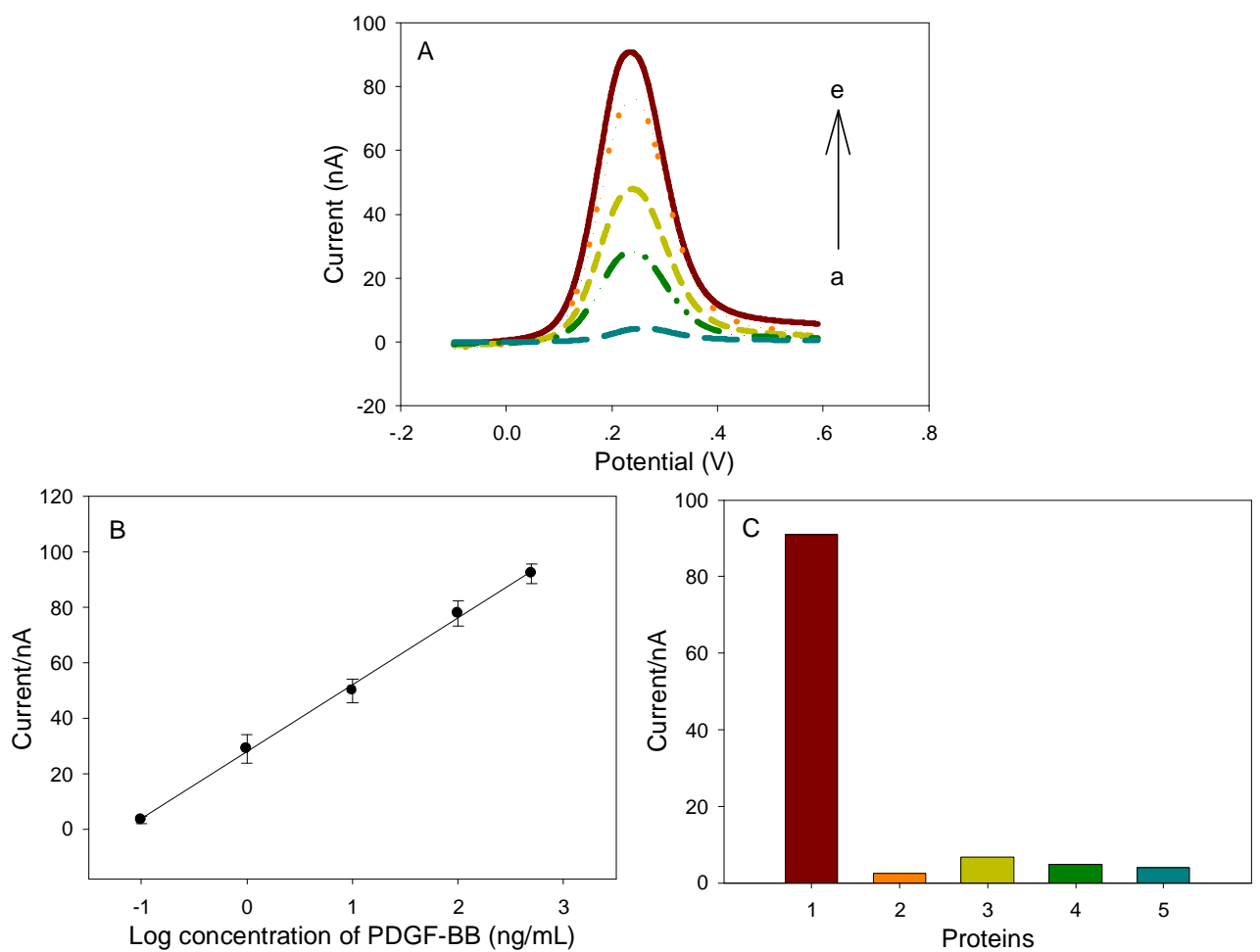

Figure 3. (A) Current response of the presented electrochemical aptasensor to target protien at different concentrations (a-e: the concentration of target protein increased gradually). (B) The linear calibration curve between the current change and Log concentration of PDGF-BB. (C) The current response of the aptasensor for different protein samples (1-PDGF-BB; 2-PDGF-AA; 3-PDGF-AB; 4-IgG; 5-BSA). 
Specificity and reproducibility. A successful biosensor should not send out false positive or false negative signals in practical application, therefore high selectivity is of significant importance. To evaluate the specificity of the presented sensor, several proteins $(1 \mu \mathrm{g} / \mathrm{mL}$ PDGF-AA, $1 \mu \mathrm{g} / \mathrm{mL}$ PDGF-AB, $1 \mathrm{mg} / \mathrm{mL}$ IgG and $10 \mathrm{mg} / \mathrm{mL} \mathrm{BSA}$ ) were investigated and the results was shown in Fig. 3C. Compared with more than $90 \mathrm{nA}$ generated from the specific reaction of aptamer probe with 500 $\mathrm{ng} / \mathrm{mL}$ PDGF-BB, the current responses initiated from other four proteins were very small, indicating that high selectivity was achieved. To evaluate the reproducibility of the proposed aptasensor, three repetitive measurements for each sample was performed and the maximum value of the relative standard deviations was $7.9 \%$.

\section{Conclusions}

In this contribution, a highly sensitive electrochemical aptasensor for protein detection was proposed based on structure switching of aptamer probe and hairpin signal probe using PDGF-BB as the model analyte. Under the optimized experimental conditions, the target protein could be sensitively detected in a relative wide linear detection range from 0.1 to $500 \mathrm{ng} / \mathrm{mL}$ with a detection limit of 0.08 $\mathrm{ng} / \mathrm{mL}$. Moreover, the presented biosensor exhibited high selectivity and good stability, making it a potential alternative for protein detection.

\section{Acknowledgements}

This study is financially supported by the National Natural Science Foundation of China (Grant Nos. 21205039, 21405023, 21205021, 21105017), Natural Science Foundation of Hunan Province (Grant Nos. 13JJ6071, 14JJ7073), Open Project of State Key Laboratory of Chemo/biosensing and Chemometrics (Grant Nos. 2013004) and Research Foundation of Education Bureau of Hunan Province (Grant Nos. 13C620, 13C622).

\section{References}

[1] G.S. Wilson, Y. Hu, Enzyme-based biosensors for in vivo measurements, Chem. Rev. 100 (2000) 2693-2704.

[2] P.E. Andreotti, G.V. Ludwig, A.H. Peruski, J.J. Tuite, S.S. Morse, L.F. Peruski, Immunoassay of infectious agents, Biotechniques 35 (2003) 850-859.

[3] S.B. Zhang, X. Hu, X.H. Yang, Q.L. Sun, X.L. Xu, X.W. Liu, G.Y. Shen, J.L. Lu, G.L. Shen, R.Q. $\mathrm{Yu}$, Background eliminated signal-on electrochemical aptasensing platform for highly sensitive detection of protein, Biosens. Bioelectron. 66 (2015) 363-369.

[4] J.W. Liu and Y. Lu, Fast colorimetric sensing of adenosine and cocaine based on a general sensor design involving aptamers and nanoparticles, Angew Chem. Int. Ed. 45 (2006) 90-94.

[5] W. Zhao, W. Chiuman, J.C.F. Lam, S.A. McMans, W. Chen, Y. Cui, R. Pelton, M.A. Brook, Y. Li, DNA aptamer folding on gold nanoparticles: from colloid chemistry to biosensors, J. Am. Chem. Soc. 130 (2008) 3610-3618.

[6] M.N. Stojanovic, P. de Prada, D.W. Landry, Fluorescent sensors based on aptamer self-assembly, J. Am. Chem. Soc. 122 (2000) 11547-11548.

[7] R. Nutiu and Y. Li, Structure-switching signaling aptamers: Transducing molecular recognition into fluorescence signaling, Chem. Eur. J. 10 (2004) 1868-1876.

[8] A.E. Radi, L.A. Sanches, E. Baldrich, C.K. O'sullivan. Reagentless, reusable, ultrasensitive electrochemical molecular beacon aptasensor. J. Am. Chem. Soc. 128 (2006) 117-124.

[9] Z.S. Wu, M.M. Guo, S.B. Zhang, C.R. Chen, J.H. Jiang, G.L. Shen, R.Q. Yu, Reusable electrochemical sensing platform for highly sensitive detection of small molecules based on structure-switching signaling aptamers, Anal. Chem. 79 (2007) 2933-2939.

[10] J.W. Liu and Y. Lu. Fast colorimetric sensing of adenosine and cocaine based on a general sensor design involing aptamers and nanoparticles. Angew. Chem. Int. Ed. 45 (2006) 90-94 